\title{
Shape Memory Alloy Based Smart Landing Gear for an Airship
}

\author{
G. N. Dayananda,,- \pm B. Varughese,,$*$ and M. Subba Rao* \\ National Aerospace Laboratories, Bangalore 560 017, India
}

DOI: $10.2514 / 1.26811$

\begin{abstract}
The design and development of a shape memory alloy based smart landing gear for aerospace vehicles is based on a novel design approach. The smart landing gear comprises a landing beam, an arch, and a superelastic nickeltitanium shape memory alloy element. This design is of a generic nature and is applicable to a certain class of light aerospace vehicles. In this paper a specific case of the shape memory alloy based smart landing gear design and development applicable to a radio controlled semirigid airship (radio controlled blimp) of $320 \mathrm{~m}^{3}$ volume is presented. A judicious combination of carbon fiber reinforced plastic for the landing beam, cane (naturally occurring plant product) wrapped with carbon fiber reinforced plastic for the arch, and superelastic shape memory alloy is used in the development. An appropriate sizing of the arch and landing beam is arrived at to meet the dual requirement of low weight and high-energy dissipation while undergoing "large elastic" (large nonlinear recoverable elastic strain) deformations to ensure soft landings when the airship impacts the ground. The soft landing is required to ensure that shock and vibration are minimized (to protect the sensitive payload). The inherently large energydissipating character of the superelastic shape memory alloy element in the tensile mode of deformation and the superior elastic bounce back features of the landing gear provide the ideal solution. A nonlinear analysis based on the classical and finite element method approach is followed to analyze the structure. Necessary experiments and tests have been conducted to check the veracity of the design. Good correlation has been found between the analyses and testing. This exercise is intended to provide an alternate method of developing an efficient landing gear with satisfactory geometry for a "certain class of light aerospace vehicles" such as airships, rotorcraft, and other light unmanned air vehicles.
\end{abstract}

$\begin{array}{ll} & \text { Nomenclature } \\ A_{f} & =\text { austenite finish temperature } \\ A_{s} & =\text { austenite start temperature } \\ E & =\text { Young's modulus } \\ M_{f} & =\text { martensite finish temperature } \\ M_{s} & =\text { martensite start temperature } \\ \delta_{h} & =\text { horizontal deflection } \\ \delta_{v} & =\text { vertical deflection } \\ \varepsilon & =\text { strain } \\ \sigma & =\text { stress } \\ \sigma_{\text {ult }} & =\text { ultimate stress }\end{array}$

\section{Introduction}

$\mathbf{T}$ HE design and development of a landing gear encompasses several engineering disciplines such as structures, mechanical systems, aerodynamics, material science, and so on. The conventional landing gear design [1] and development for aerospace vehicles is based on the availability of several critical components/ systems such as forgings, machined parts, mechanisms, sheet metal parts, electrical systems, hydraulic systems, and a wide variety of materials such as aluminum alloys, steel, titanium, beryllium, and polymer composites. As the science of materials is progressing continuously it is natural that the use of new materials will replace older designs with new ones.

Energy absorption and crashworthy features are the primary design criteria that govern the development of landing gears.

Received 27 July 2006; revision received 7 April 2007; accepted for publication 18 April 2007. Copyright @ 2007 by the American Institute of Aeronautics and Astronautics, Inc. All rights reserved. Copies of this paper may be made for personal or internal use, on condition that the copier pay the $\$ 10.00$ per-copy fee to the Copyright Clearance Center, Inc., 222 Rosewood Drive, Danvers, MA 01923; include the code 0021-8669/07 \$10.00 in correspondence with the CCC.

${ }^{*}$ Scientist, Advanced Composites Division, P.O. Box 1779, Airport Road.

${ }^{\dagger}$ Scientist, Advanced Composites Division, P.O. Box 1779, Airport Road; dayanand@css.nal.res.in; gndayananda@yahoo.com (Corresponding Author).
Del Monte [2] deals with the design and development of a crashworthy landing gear for rotorcraft that dissipates crash landing energy. Airodli et al. [3] deals with the design of the crashworthy landing gear adopting a crash tube as an energy-absorbing device in crash conditions. In this design a light alloy thin-walled tube is mounted coaxially to the shock absorber cylinder and during the severe impact condition, this collapses to enhance the energy absorption performance of the landing system. Like the landing gear of fixed wing aircraft, the landing gear of helicopters has also evolved over the past few decades. The different variants of helicopter landing gear include the wheeled gear, tricycle, quadricycle arrangements and the skid type landing gear. Among these, the skid type of landing gear for the helicopter has gone through extensive design and development and is now used in many helicopters as it meets their requirement.

Philips et al. [4] deals with the design of a crashworthy landing gear for helicopters which would lessen the magnitude of crash forces. In this design the skid stiffness was idealized as a bilinear curve. The first part of the curve represents elastic deformation and the second part plastic deformation of the skid.

Cheng-Ho Tho et al. [5] refers to the design and development of a high energy absorbing skid landing gear for helicopters. Stephens et al. [6] deals with the development of a dynamic analytical methodology for analyzing the structural behavior of a helicopter skid gear during a high-energy landing. This methodology was used in the correlation of impact loads for level landing at different conditions. Airoldi et al. [7] presents a numerical approach to the optimization of skid landing gears. The optimization technique is applied to investigate the tradeoff between landing performances and gear strength. Ashish et al. [8] discusses a nonlinear finite element based method of analyzing the structural behavior of helicopter skid gears during a high-energy landing.

Another class of energy-absorbing devices is skis, which are used for skiing on snow-filled surfaces, and their function is similar to that of skids in aircraft. Of late, a swiss ski [9] producer has tested composite skis in which laminated $\mathrm{Cu}-\mathrm{Zn}-\overline{\mathrm{A}}$ l shape memory alloy (SMA) strips are embedded to improve energy-absorbing characteristics. The serious shortcoming in the designs in which 
SMA elements are completely embedded in the polymer composites is that the straining of the SMA element is limited by the allowable design strains of the polymer composite (normally around $0.5 \%$ ). Unless the SMA elements are strained at least in the range of 3-4\% the energy absorption capability remains largely underexploited. Despite all the developments and advances in the skid and ski landing gear design discussed above, there is still substantial scope to reduce the weight of the landing gear further by incorporating new materials and novel designs.

The metallic skids discussed above [3-5] are generally designed to attenuate the energy generated during normal landings by elastic deformation. Many times they undergo permanent plastic deformation in response to the impact energy of a crash landing. The plastic deformation of metal skids absorbs a significant percentage of the crash landing energy. The drawbacks of such a type of metallic skids are the landings are hard (they do not protect the sensitive gadgets) and require frequent replacement because of the hard landings. The metallic replacement of these skids is labor intensive and expensive, and further they do substantially add to the weight.

Ideally an efficient skid must have high shock absorption capability (during landing), be affordable, possess low weight, endure a sufficient number of cycles without undergoing permanent plastic deformation, have high-energy absorption efficiency, and facilitate easy maintenance and replacement of worn-out parts. The present effort aims to develop such an efficient landing gear system incorporating superelastic SMA elements and polymer based carbon composites for aerospace vehicles that overcome the drawbacks of the skids/skis mentioned earlier. Polymer carbon composites are ideally suited for the design and development of an efficient skid as they have high specific stiffness and high specific strength compared with conventional materials used for landing gear construction. Along with these composites if superelastic shape memory alloys are effectively integrated, then it opens up enormous opportunities to develop novel, highly efficient, structural/mechanical subsystems whose functions can be tailored to meet specific requirements. In such an intelligent and novel design, the superelastic SMA element along with the polymer composite should be made to undergo "large elastic" deformations and possess low recoil stress to improve

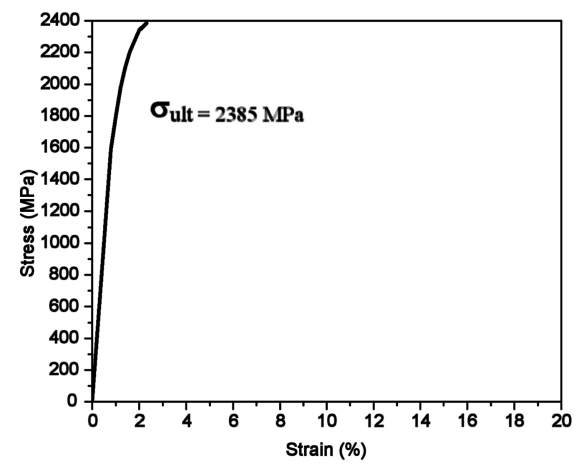

a)

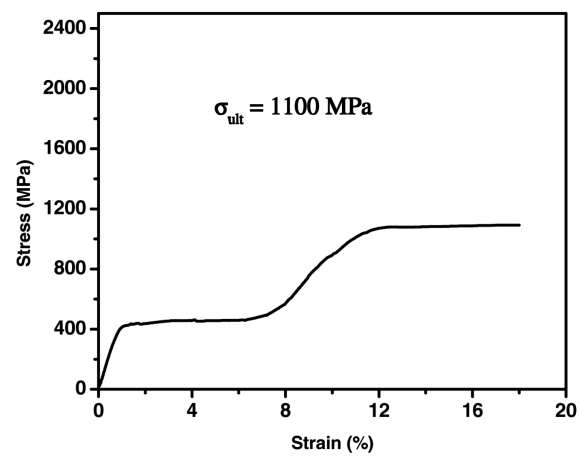

$\begin{array}{ccc}\text { c) } & \text { d) } \\ \text { Fig. } 1 & \text { Stress-strain curve for a) high carbon spring steel wire; b) al }\end{array}$

b) stability characteristics. Research papers in which superelastic SMA elements are effectively integrated along with polymer composites on the lines just discussed are scanty in the literature. The specific case of the SMA based smart skid landing gear design and development applicable to a radio controlled semirigid airship (RC blimp) of $320 \mathrm{~m}^{3}$ volume is explained in this paper. It has to be pointed out here that the SMA based smart skid landing gear is more relevant to a "certain class of light aerospace vehicles." The certain class of light aerospace vehicles here refers to those vehicles (smaller airships, rotorcraft, and other unmanned air vehicles) where the landing speeds are typically less than $2 \mathrm{~m} / \mathrm{s}$, weight of the vehicle is less than about $2500 \mathrm{~N}$, and the landing gear weight budgets are typically less than $5 \%$ of the total weight of the vehicle. The design could, however, be extended to a larger class of vehicles.

\section{Energy-Absorbing Materials and Superelastic Shape Memory Alloy}

Among the several energy-absorbing materials, the commonly used materials for aerospace structural applications [10] are carbon spring steels, rubber, honeycomb core, and some types of foams. Different types of energy-absorbing mechanisms have been conceived and built using these materials. The superelastic SMA's are a new class of materials which are very strong candidates for repeated use as energy-absorbing devices, particularly when they are made to undergo large elastic deformation in tensile mode. The term large elastic strain in this paper refers to the large stress-induced superelastic strain which is completely recoverable (when the stress is removed). Also, the elastic recoil in these materials takes place at a relatively much lower value of stress, which ensures better structural stability of the vehicle during the recoil period.

To bring out the superior energy-absorbing/dissipating capabilities of the nickel-titanium superelastic material that has been used in this development, it has been compared with the conventional carbon spring steel, structural steel, and aluminum alloy. It is clear that superelastic material is not only far superior in terms of energy absorption but it also has a lower level of recoil stress, which imparts better stability characteristics. This is shown in Figs. 1a-1d (with typical values) and Table $\underline{1}$.
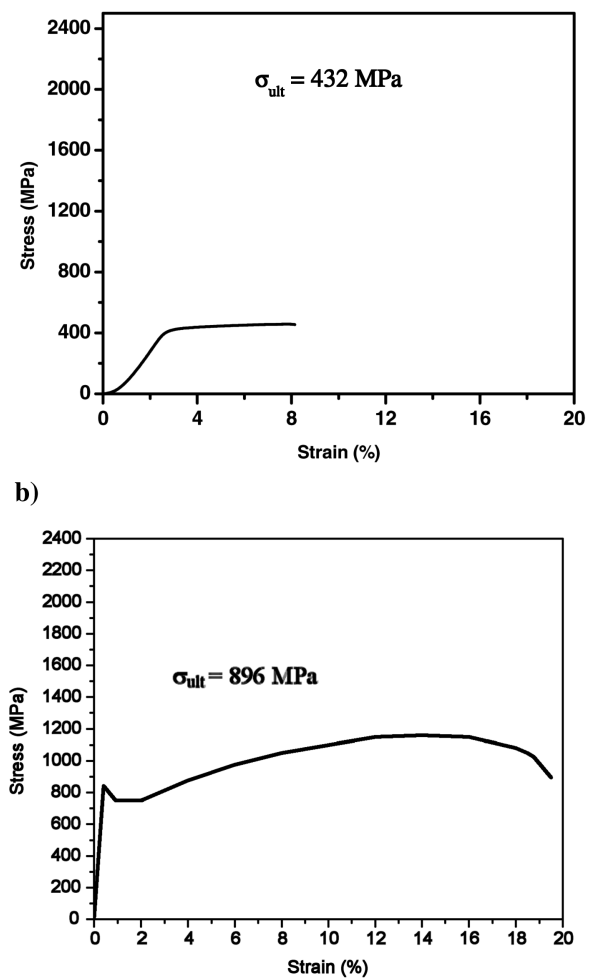

d) 
Table 1 Comparison of energy absorption of four different materials

\begin{tabular}{lcc}
\hline \hline & $\begin{array}{c}\text { Energy absorption in elastic } \\
\text { region, J/cc }\end{array}$ & $\begin{array}{c}\text { Elastic recoil } \\
\text { stress, MPa }\end{array}$ \\
\hline $\begin{array}{l}\text { High carbon spring } \\
\text { steel }\end{array}$ & 6.42 & 1590 \\
$\begin{array}{l}\text { High strength structural } \\
\text { steel }\end{array}$ & 1.8 & 800 \\
$\begin{array}{l}\text { Superelastic NiTi SMA } \\
\text { Aluminum }\end{array}$ & 60.0 & 100 \\
\hline \hline
\end{tabular}

Shape memory alloys are materials that have the unique ability to recover their original shape after undergoing large deformations at a given temperature either through heating (referred to as the shape memory effect) or by the removal of the external load (referred to as the superelastic effect). These properties are the manifestations of a reversible martensitic phase transformation occurring in the system between a crystallographically high-symmetry (cubic crystal structure) austenite phase to low symmetry (monoclinic crystal structure) martensite phase. The schematic representation of mechanical behavior as a function of temperature, strain, and stress is summarized in Fig. 2 [11]. The SMA exhibits the shape memory effect when deformed below the martensite finish temperature $M_{f}$. These deformations (below $M_{f}$ ) are recovered by heating the material above the austenite finish temperature $A_{f}$. The SMA is in its parent austenite phase above $A_{f}$. Stress-induced martensite (SIM) is formed when the austenite is stressed (loaded) to a certain level (above $A_{f}$ ). On removal of load, the stress-induced martensite reverts to austenite at a lower stress, thereby resulting in the superelastic behavior. The resulting nonlinear stress-strain relationship results in a hysteresis. As the test temperature is increased, the stress at which the SIM forms also increases. Beyond a temperature designated as $M_{d}$, true plastic deformation occurs in place of SIM.

The hysteresis is typically $150-300 \mathrm{MPa}$ in Ni-Ti base alloys and results in the dissipation of energy during superelastic loading and unloading. This mechanism of energy dissipation during deformation of the material is used here to dissipate the energy of impact during landing. This process holds for a wide range of strain rates. Superelastic shape memory alloys are being tried out as energy-dissipating elements for several possible applications [1114]. The superelastic SMA element is used here not only as an energy-dissipating element but also as a strain sensor, thereby exploiting the bifunctionality of the superelastic SMA element. The details are discussed in the following sections.

\section{Smart Landing Gear for the Radio Controlled Blimp}

The RC blimp is a nonrigid airship. It is used for weather monitoring, pollution monitoring, disaster management, traffic management, and other purposes. Helium gas is used to generate the

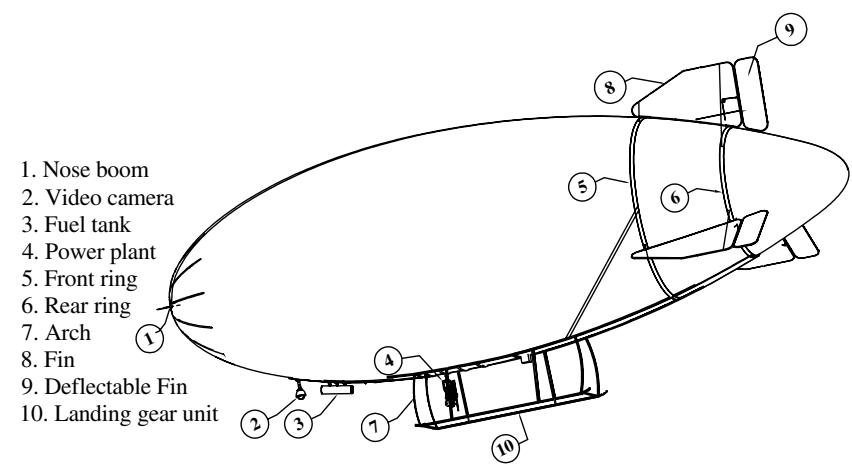

Fig. 3 Radio controlled blimp.

lift for the blimp while a fixed engine provides the thrust. The RC blimp shown in Fig. 3 has a $320 \mathrm{~m}^{3}$ volume, measures $18 \mathrm{~m}$ long, and has a maximum diameter of $6 \mathrm{~m}$. It is radio controlled from the ground and comprises various subsystems such as controls, payload comprising camera, propulsion, envelope, structural framework to hold the envelope, and the landing gear. The structural framework shown in Fig. 3 comprising two rings and the landing gear is built using primarily carbon composites. The structural framework serves as a base to mount the fin and rudder units in addition to holding the envelope. The landing gear serves the purpose of absorbing impact energy during landing. The impact energy during landing can cause severe shock and therefore render these gadgets ineffective and even damage them. Therefore, the landing gear (comprising landing beam, arch, and superelastic SMA element) shown in Fig. 4 has to be designed in such a way that it absorbs the maximum impact energy during landing.

The inputs considered in the design of landing gear [15] are as below:

1) The maximum gas lift for a $320 \mathrm{~m}^{3}$ airship is $2800 \mathrm{~N}$; the reaction load is assumed to be $60 \%$ of this value (descent rate of $1.5 \mathrm{~m} / \mathrm{s}$; for a gondola treated as a rigidly connected member), which is $1680 \mathrm{~N}$. Applying a factor of safety of 1.5 on this load, an ultimate load of $2500 \mathrm{~N}$ is considered.

2) During landing the skid is assumed to make an angle of $20 \mathrm{deg}$ with the ground.

3) Because there are two identical subsegments of the skid, each segment will take half of the load, that is, $1250 \mathrm{~N}$.

To prove the relative superiority of superelastic SMA based carbon fiber reinforced smart landing gear, it was considered appropriate to design a conventional aluminum metal landing gear consisting of a helical tensile spring in one option and a compression spring in another. These two options were evaluated against the SMA based carbon fiber reinforced plastic (CFRP) smart landing gear. The comparison between the landing gears is clearly brought out in Fig. 5 and Table 2. It is very clear from the table that the superelastic SM $\bar{A}$ based carbon fiber reinforced smart landing gear weighs far less than

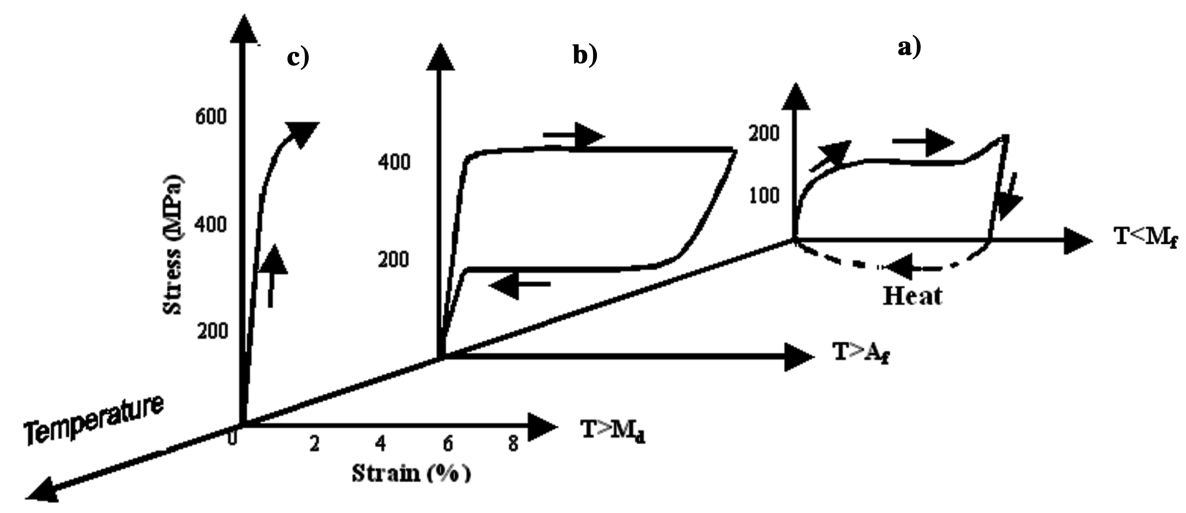

Fig. 2 Schematic representation of the stress-strain temperature showing a) shape memory; b) superelasticity; and c) ordinary plastic deformation. 


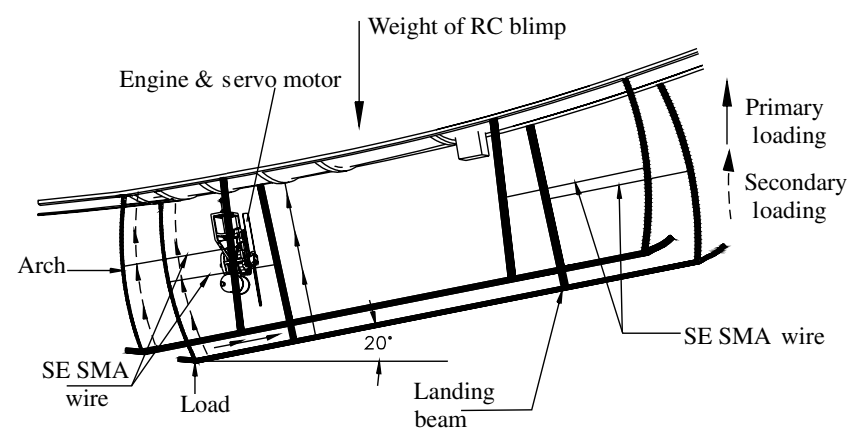

Fig. 4 Landing gear.

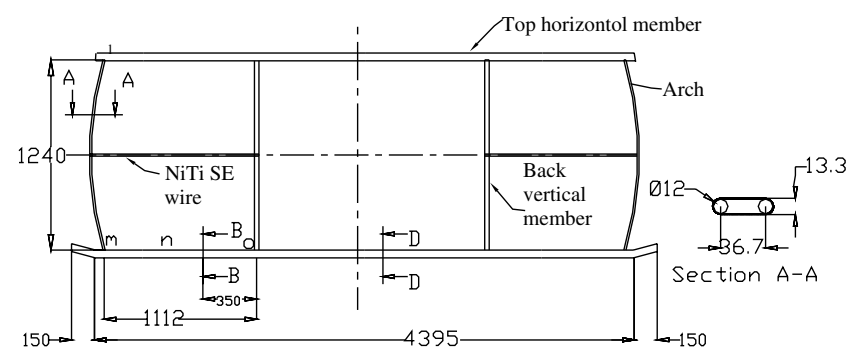

CFRP skid with superelastic NiTi SMA

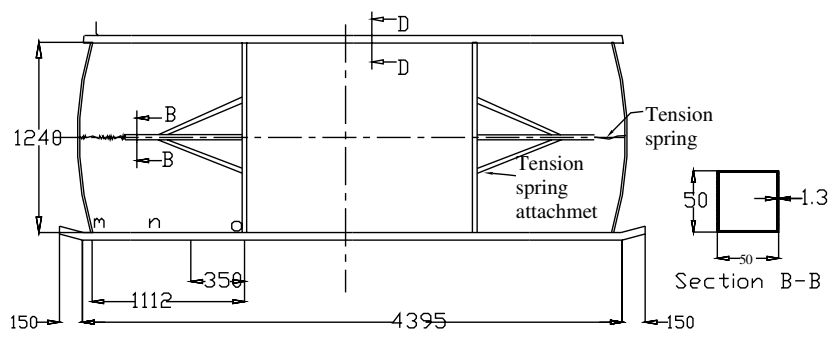

Metal skid with tension springs

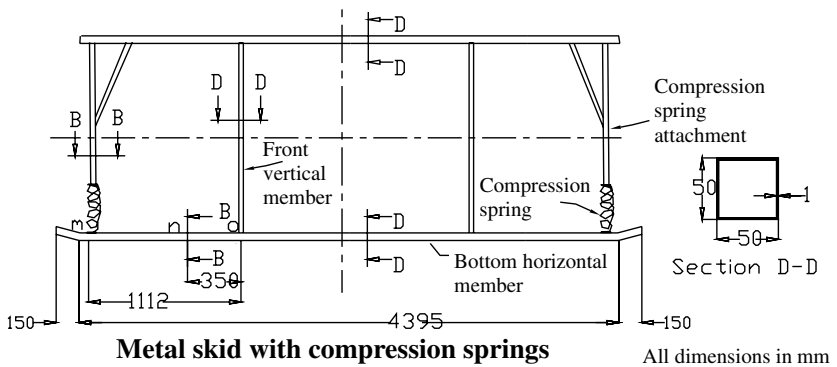

Fig. 5 Comparison of different landing gears.

an equivalent aluminum landing gear either with a helical tensile spring or a compression spring.

Further, even within the smart landing gear the superelastic SMA was replaced with a steel wire and the relative superiority of using the superelastic SMA wire along with the CFRP arch is thoroughly

Table 2 Comparison of the landing gear performance using different materials

\begin{tabular}{lccc}
\hline \hline Parameters & $\begin{array}{c}\text { Superelastic } \\
\text { SMA based } \\
\text { CFRP smart } \\
\text { landing gear }\end{array}$ & $\begin{array}{c}\text { Aluminum } \\
\text { landing gear } \\
\text { with tensile } \\
\text { spring }\end{array}$ & $\begin{array}{c}\text { Aluminum landing } \\
\text { gear with } \\
\text { compression } \\
\text { spring }\end{array}$ \\
\hline $\begin{array}{l}\text { Weight, } \mathrm{N} \\
\begin{array}{c}\text { Maximum } \\
\text { deflection, }\end{array}\end{array}$ & 160 & 257.35 & 247.47 \\
$\quad 48$ & 48 & 48 \\
mm & & & \\
$\begin{array}{l}\text { Maximum } \\
\text { load, } \mathrm{N}\end{array}$ & 2500 & 2500 & 2500 \\
\hline \hline
\end{tabular}

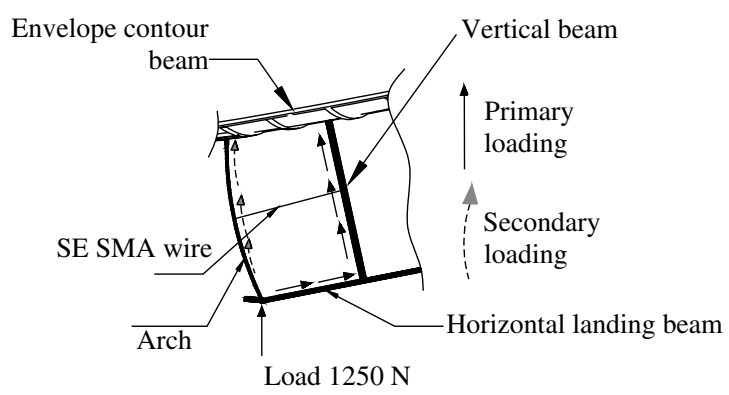

Fig. 6 Enlarged view of subunit.

discussed. To ensure soft landing in this design a part of the landing gear referred to as the arch which incorporates a satisfactory configuration in terms of geometry and weight of natural cane, carbon composites, and NiTi based superelastic shape memory alloy is designed to undergo large elastic deformations and can be expended after using it for a fixed number of cycles (typically a few hundred). The arch is connected to a landing beam which first experiences the load during impact while landing. Figure $\underline{6}$ is an enlarged view of the landing gear subunit comprising one arch, a horizontal landing beam, a vertical beam, and part of the envelope contour beam. The landing gear is made of composite material such as CFRP, glass fiber reinforced composite, cane, and superelastic shape memory alloy. Figure $\underline{7}$ shows the details of landing beam where $1-m$ refers to the arch and $m-n-o$ to the segment of the landing beam, which first sees the impact. The thickness of the segment is minimum in the range $m-n$ (i.e., constant) and is varying from $n$ (section B-B) to o with a maximum at o (section C-C) as shown in the same figure. The arch cross section (Fig. 8a) shows the thin CFRP layer wrapped around the cane, which is the core (as well as the structural reinforcing element for the arch). The core is generally required only to provide the shear stiffness. However, here because the arch has to undergo large elastic deformations the core has to possess both shear and longitudinal stiffness. Being a highly fibrous material having low density the cane was chosen here as the reinforcing core. The cane enables the arch to undergo large elastic deformation.

The fabrication of the landing gear is done using wet layup technique with LY-5210 resin and HY-932 hardener. After several trials of different combinations, the natural cane material wrapped with CFRP B.D fabric proved to be the satisfactory choice meeting the requirement of adequate elastic deformations and minimum weight. The arch is curved outwards and while loading (during impact) the curvature further increases as shown in Fig. 9. When the superelastic SMA is connected to the arch the SE SMA element is in tension. The arch and the SMA together provide the required compliance, which is required to achieve large elastic deformations. The blimp design assumes the landing to be nose down at an inclination of about $20 \mathrm{deg}$ to the ground (Fig. 4). To take care of the unforeseen nose up landings the landing gear subunits are mirrored about the vertical axis (Fig. 5). Therefore, the construction of the landing gear unit is symmetric about this axis shown in Fig. 7. The landing gear is effective for landing at inclinations less than $\overline{20} \mathrm{deg}$ also.

\section{Material and Testing Details}

The material used for the study was $0.6 \mathrm{~mm}$ superelastic NiTi SMA wire. The chemical composition of the wire was $\mathrm{Ni}=54.3 \%$ and $\mathrm{Ti}=45 \%$. The transformation temperatures obtained from the DSC tests were as follows:

$M_{f}=6.8 ; M_{s}=12.5 ; A_{s}=11.9$, and $A_{f}=17.5^{\circ} \mathrm{C}$, respectively. The length of the wire used for the testing was $1000 \mathrm{~mm}$. The specimens were straight and of uniform cross section.

The modulus of the arch and beam are obtained from test specimens cut from the actual component using a Zwick Universal Testing Machine (UTM). The load cells used in the experiment were also calibrated using the same UTM. The displacements were 


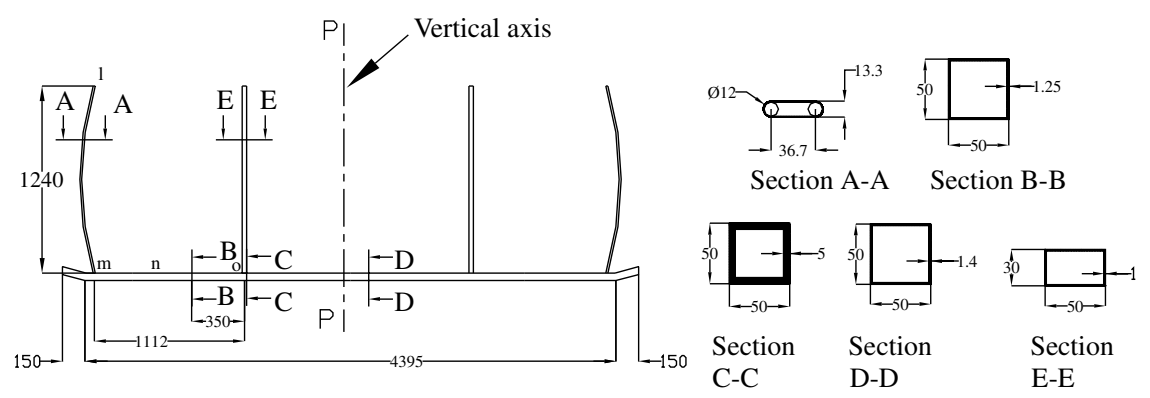

Fig. 7 Details of landing gear.
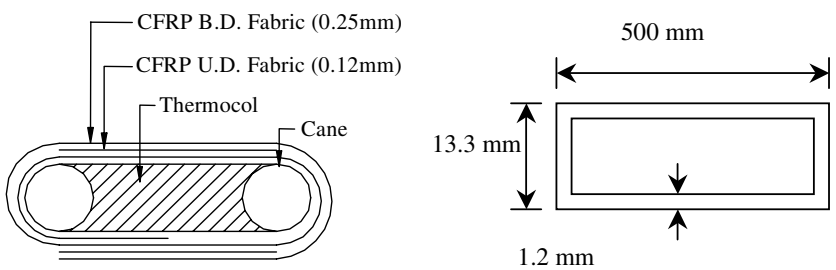

a)

b)

Fig. 8 a) Cross-section view of arch; b) equivalent section of arch used in FE model.

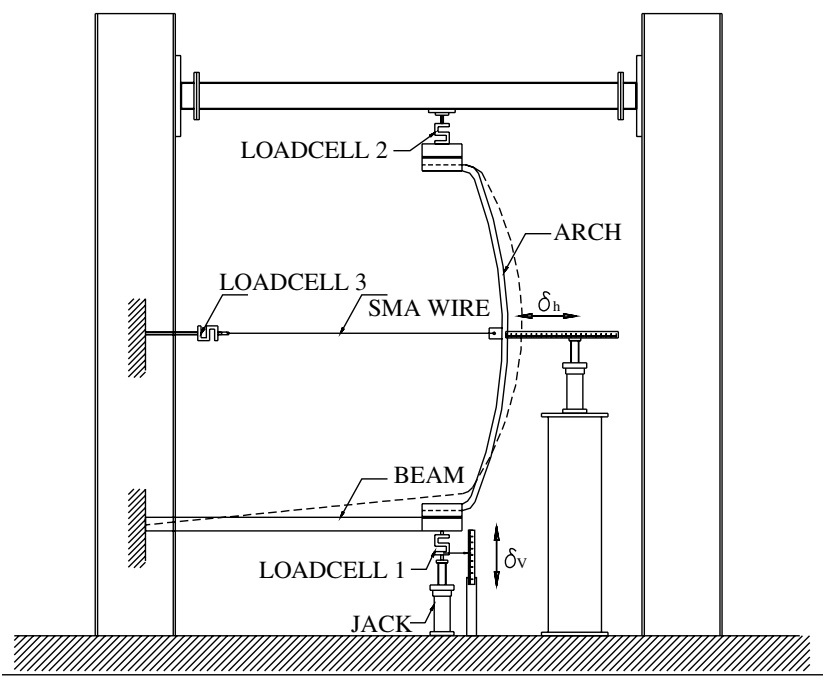

Fig. 9 Experimental setup for arch and landing beam segment testing using SMA.

crosschecked using a Micro Epsilon laser sensor. Data acquisition was done using a National Instruments card.

The experiments were conducted for three configurations. For configuration 1, the subunit comprises a segment of the landing beam, CFRP arch with cane, and SMA. Configuration 2 is the same as configuration 1 but without SMA and for configuration 3 the SMA

Table 3 Summary of experimental results (deflection)a

\begin{tabular}{lrcc}
\hline \hline & $\mathrm{C} 1$ & $\mathrm{C} 2$ & $\mathrm{C} 3$ \\
\hline Maximum vertical load, $\mathrm{N}$ & 1200 & 1000 & 1200 \\
$\delta_{h}$ at $1000 \mathrm{~N}$ load, mm & 40 & 51 & 11.5 \\
$\delta_{v}$ at $1000 \mathrm{~N}$ load, mm & 37 & 42 & 20 \\
$\delta_{h}$ at $1200 \mathrm{~N}$ load, mm & 51 & - & 15.5 \\
$\delta_{v}$ at $1200 \mathrm{~N}$ load, mm & 45 & - & 25 \\
$\delta_{h}$ at $1250 \mathrm{~N}$ load, mm & 55 & - & - \\
$\delta_{v}$ at $1250 \mathrm{~N}$ load, mm & 49 & - & - \\
\hline \hline
\end{tabular}

${ }^{\mathrm{a}} \mathrm{C} 1$ : configuration 1 (with SMA); C2: configuration 2 (without SMA); C3: configuration 3 (with steel wire). was replaced with the steel wire. In all the three configurations the load was applied at the point shown in Fig. 9. The length of the landing beam subsegment considered for tests was $1112 \mathrm{~mm}$, and the height of the arch was $1240 \mathrm{~mm}$. Load cell 1 monitors the total vertical load. Load cell 2 monitors the load taken by the arch. Load cell 3 monitors the SMA load and steel wire load for configurations 1 and 3 . The $\delta_{v}$ was measured using linear scales as shown in Fig. 9. Table $\underline{3}$ summarizes the experimental results.

\section{Smart Landing Gear Subunit}

The landing gear is designed to have two load paths, namely, a primary load path and a secondary load path. The primary load path comprises the landing beam and vertical beam as shown in Fig. 4 . The secondary load path is the arch made of carbon composites and cane and incorporates the SMA element. The primary load path is designed to resist a larger share of the impact load and have longer life. The secondary load path members which are the arch and the SMA are designed to resist relatively lesser amount of load while undergoing large elastic deformations and in the process dissipate the impact energy in the form of heat. The elements in the secondary load path are to be replaced after a fixed number of cycles, which is typically a couple of hundred cycles as already mentioned. The sequence of the energy dissipation process in the landing gear subunit is illustrated through Figs. 10a-10d (idealized). The position of the tracer (filled circle) indicates the stress-strain level at different times. For the purpose of clarity it is assumed that the impact-loading event will last for a period of $2 \mathrm{~s}$. As is clear from the figure, at $t=0 \mathrm{~s}$, the superelastic SMA is placed in the arch such that the strain level is about $0.5 \%$ (given prestrain) and the stress level is around $100 \mathrm{MPa}$, that is, the initial position of the tracer is below the unloading stress. At $t=1 \mathrm{~s}$, when the impact event takes place the stress reaches a value that is close to the superelastic plateau stress, which is greater than $400 \mathrm{MPa}$ and the strain level is over $1 \%$. At $t=2 \mathrm{~s}$, the superelastic strain level greater than $5 \%$ is reached, at more or less a constant value of plateau stress, along with a corresponding large elastic deformation of the CFRP arch. At $t=3 \mathrm{~s}$, the unloading of the SMA takes place, which is simultaneous with the recoil of the landing gear. The austenite gets converted to martensite while undergoing the large superelastic strain (loading plateau) and gets reconverted to austenite while undergoing the large superelastic strain recovery (unloading plateau). The unloading plateau stress is also referred to as the recoil stress and the recoil takes place at a relatively much lower value of stress. This feature enhances the stability characteristics of the vehicle during the recoil period. The event at $t=2$ and $t=3 \mathrm{~s}$ together constitute the process of energy dissipation and elastic recoil in the landing gear subunit. In total there are four such subunits in the landing gear, two subunits in the front and two in the rear as shown in Fig. 4. For testing and analysis only one subunit (comprising an arch, SMA element, and a landing beam) is considered. Testing and analysis has not been done on the whole landing gear.

\section{Analysis}

During the preliminary design stage the sizing of the arch and beam was done based on the classical strength of materials approach. To simplify analysis during this stage the arch and beam were 


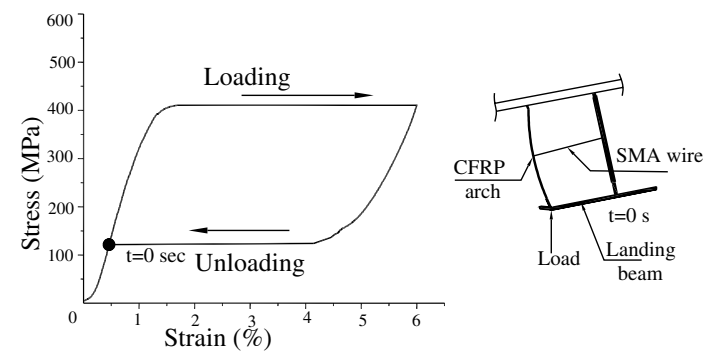

a)
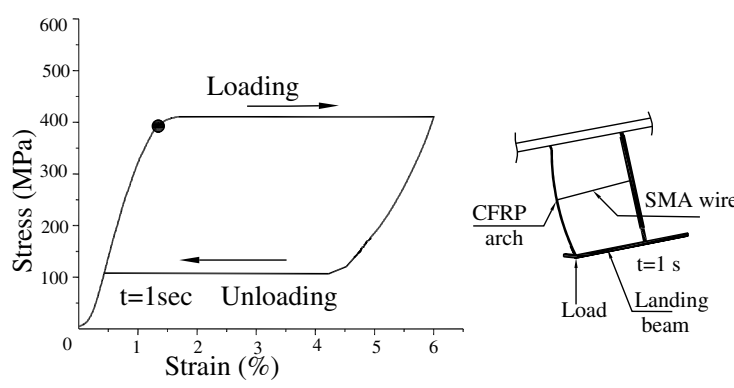

b)
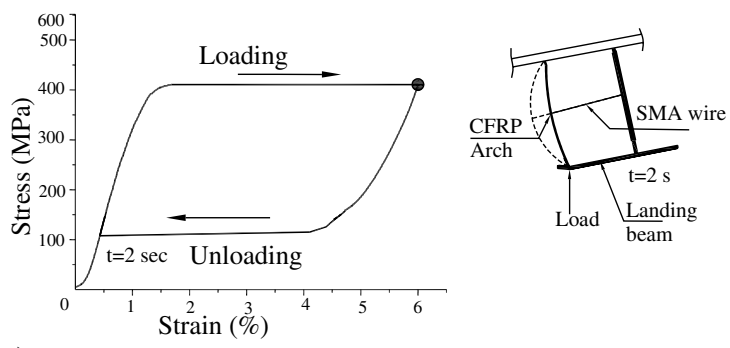

c)
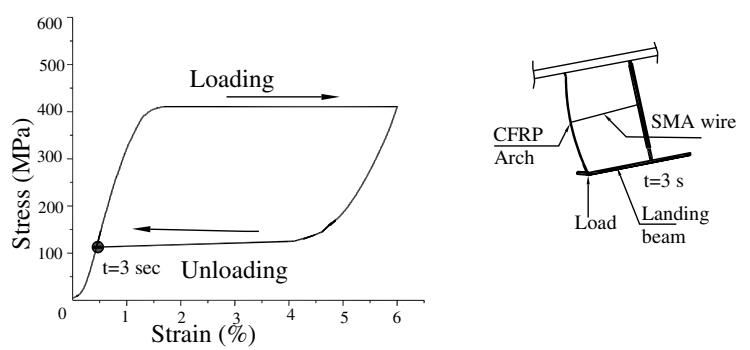

d)

Fig. 10 a) Initial position $(t=0$ ); before impact; $\sigma \approx 100 \mathrm{MPa} ; \varepsilon \approx$ $0.5 \%$ in SMA. b) $t=1$; just impacted; $\sigma>400 \mathrm{MPa} ; \varepsilon \approx 1 \%$ in SMA. c) $t=2$, full impact load transfer [maximum elastic deformation (shown exaggerated) of arch and extension of SMA] $\sigma \approx 500 \mathrm{MPa} ; \varepsilon>5 \%$ in SMA element. d) $t=3$, retraction of landing gear and unloading of SMA; $\sigma \approx 100 \mathrm{MPa} ; \varepsilon \approx 0.5 \%$ in SMA.

considered separately. The sizing of the two components was based on the assumed load-sharing requirement and their individual deflections were computed. When the arch and beam are combined together along with SMA it is cumbersome to get load sharing and deflections of the arch and the beam from a classical approach. Hence a finite element analysis has been carried out.

Static tests conducted on the arch and the arch-SMA combination showed a nearly nonlinear load-deflection pattern. In the entire setup of the landing gear, the nonlinear behavior is primarily due to the geometric nonlinearity associated with the arch. To compare the predictions of the FE model with the test results a nonlinear FE analysis is carried out using MSC/NASTRAN. The analysis is done for both $\mathrm{C} 1$ and $\mathrm{C} 2$ configurations. The arch and beam are modeled with the beam elements (CBEAM) and the SMA wire is modeled with the CELAS element in NASTRAN. The beam consists of 15 elements, the arch consists of 20 elements and the SMA wire is modeled with 1 element. Preliminary convergence studies were done before finalizing the FE model.

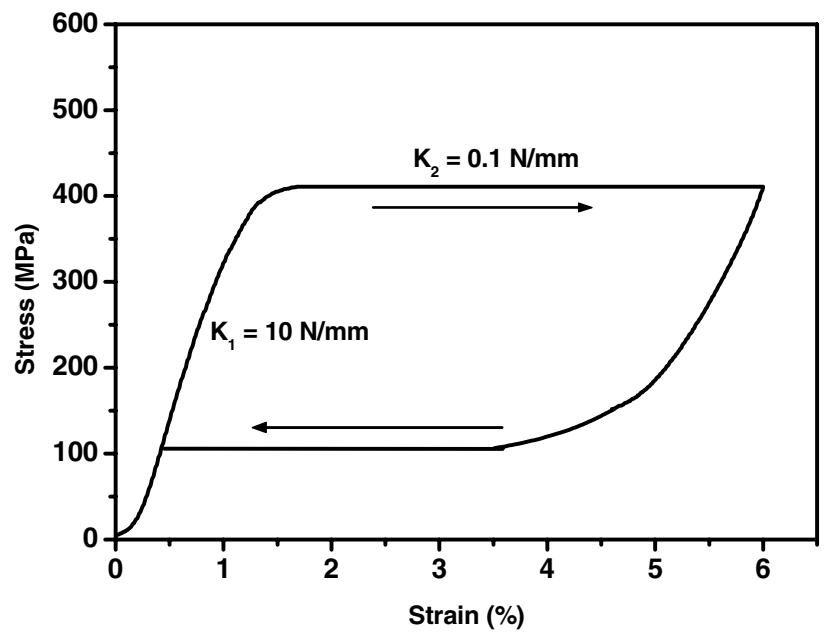

Fig. 11 Equivalent SMA linear spring stiffness $(1.5 \mathrm{~N} / \mathrm{mm})$ for $\mathrm{FE}$ model.

The beam cross section is modeled in the finite element method (FEM) as a hollow section of $50 \mathrm{~mm} \times 50 \mathrm{~mm}$. The beam is fabricated by a wet layup process using bidirectional CFRP material with $[0 / 90 \mathrm{deg}]$ orientation. For the beam, an equivalent modulus of $30 \mathrm{GPa}$ obtained from tests conducted on specimens cut from actual test component is used. It may be noted that the modulus obtained here is lower than that normally found in published literature. The reduction in modulus can be attributed to factors such as fabrication process, deviation in fiber orientation, environmental effects, and so on. The arch is modeled here as an equivalent rectangular cross section of $50 \mathrm{~mm} \times 13.3 \mathrm{~mm} \times 1.2 \mathrm{~mm}$. The area of the equivalent arch section is adopted through the rule of mixtures considering the areas and moduli of both cane and CFRP layers wound over the cane section as shown in Fig. 8b. A modulus of $14 \mathrm{GPa}$ is used for the arch section in the analysis. The SMA behavior is modeled as a bilinear spring element having stiffness $K_{1}$ and $K_{2}$. The elastic deformation of the austenite (segment 1) is given a stiffness value $K_{1}=$ $10 \mathrm{~N} / \mathrm{mm}$ and the plateau region (segment 2) a stiffness value $K_{2}=0.1 \mathrm{~N} / \mathrm{mm}$ (see Fig. 11 ).

\section{Results and Discussion}

This section focuses on the following aspects of the landing gear:

1) The combined benefit of CFRP beam, natural cane reinforced CFRP arch and SMA.

2) The role of the SMA element as an energy-absorbing member.

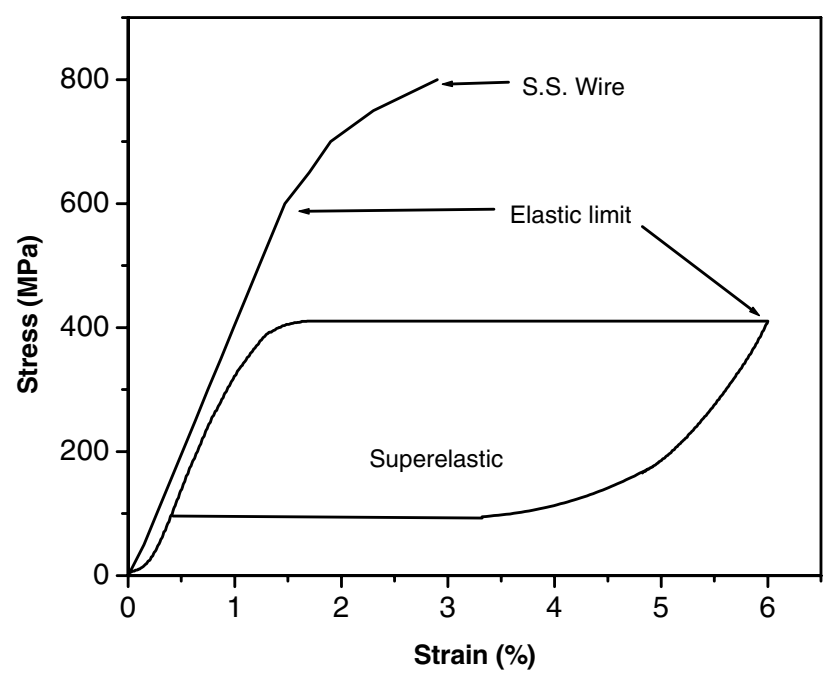

Fig. 12 Comparison of superelastic SMA and stainless steel wire. 


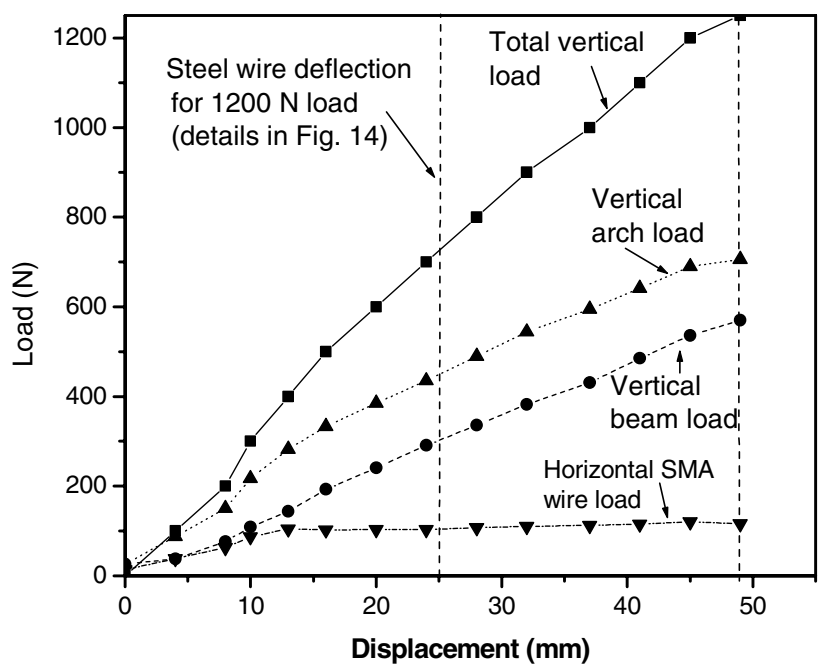

Fig. 13 Load vs vertical deflection for $\mathrm{C1}$.

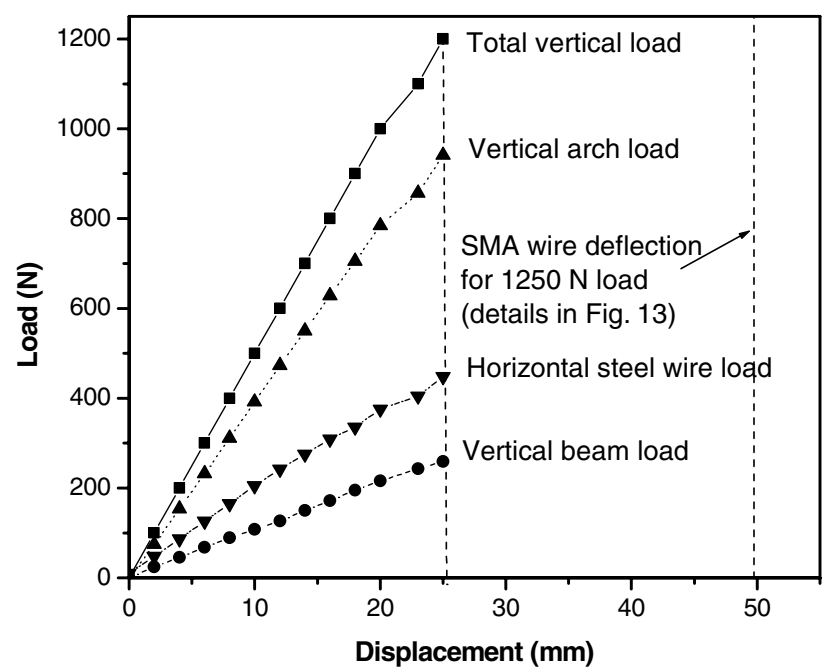

Fig. 14 Load vs vertical deflection for C3.

3) The comparison of SMA wire with a steel wire for energy dissipation.

4) The bifunctionality of the SMA element.

As already discussed the experiments are done for three configurations, namely $\mathrm{C} 1, \mathrm{C} 2$, and $\mathrm{C} 3$. Figure 12 shows the comparison of the superelastic SMA and stainless steel wire. If on the other hand a steel wire of identical diameter as the SMA element is used, then, because the maximum elastic deformation of the steel element is less than $2 \%$ (as opposed to $6-8 \%$ for the superelastic SMA) and the modulus is far higher than the superelastic SMA, therefore the compliance of the landing gear subunit will be quite different from the case of using SMA wire. Also, the more important aspect is that in the elastic region an identical mass of the steel wire will dissipate very little energy compared with the superelastic SMA element during the loading-unloading cycle.

This will affect not only the load sharing between the arch and the beam but also the magnitude of the elastic deformation of the landing gear unit (i.e., the deformations will be far less than desired and therefore the energy dissipated will also be very low). Also, the steel wire does not possess sensory characteristics like the superelastic SMA described earlier. To validate the design concept, a steel wire of identical dimensions as that of SMA wire was used in the experiment and the subunit was loaded up to $1200 \mathrm{~N}$. This case is referred to as configuration 3 . The loading was stopped at $1200 \mathrm{~N}$ as signs of failure were noticed (i.e., some unusual acoustic activity was observed).

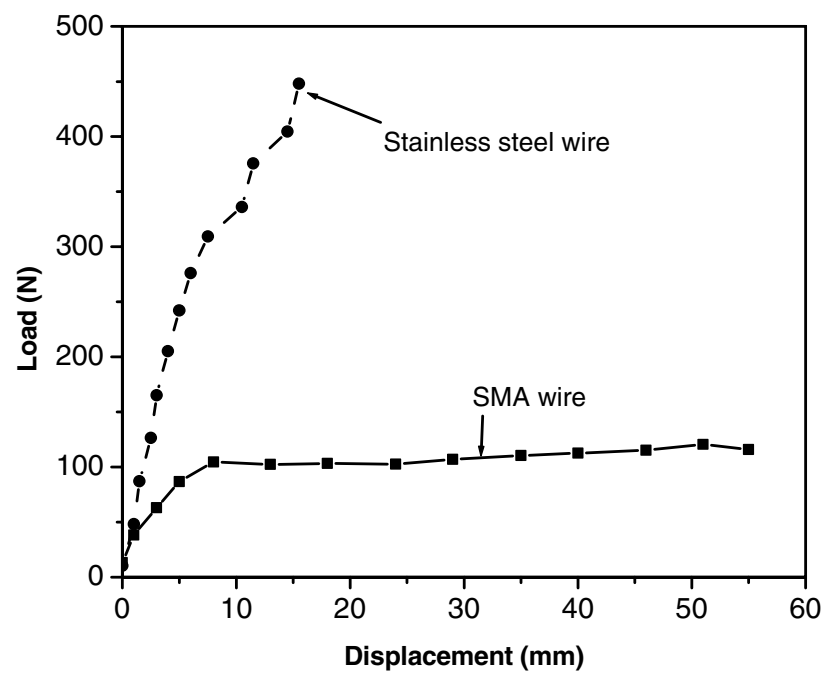

Fig. 15 Load vs horizontal deflection for stainless steel and SMA wire (from $\mathrm{C} 1$ and $\mathrm{C3}$ ).

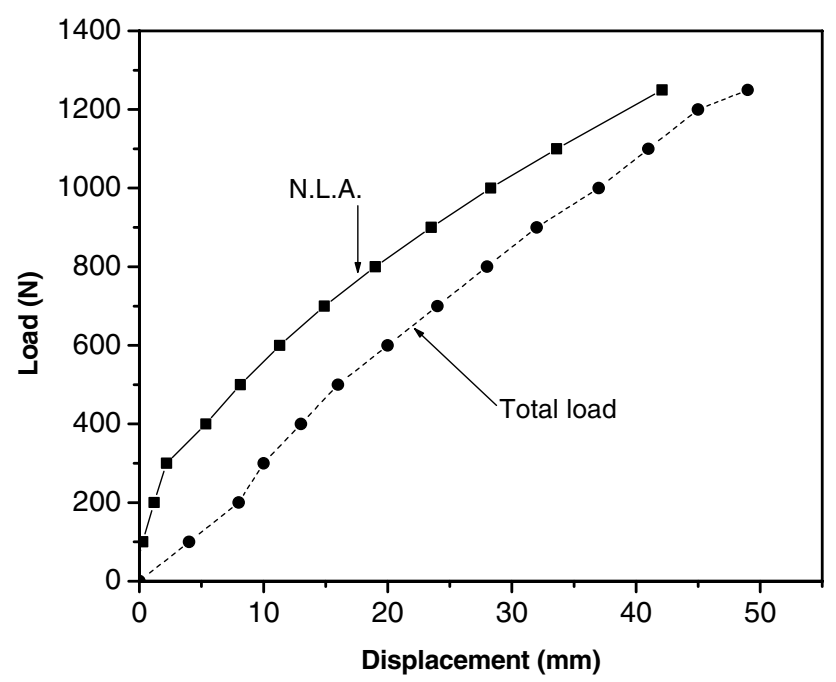

Fig. 16 Comparison of nonlinear analysis and experimental result; load vs vertical deflection $\left(\delta_{v}\right)$ for $\mathrm{C} 1$.

The focus of the analysis and tests is on the vertical deflection and load sharing of the arch and beam. The comparison of load vs vertical deflection for the subunit using SMA and steel wire is given in Figs. 13 and 14. The load vs horizontal deflection for stainless steel and SMA is shown in Fig. 15. When the steel wire is fixed in place of SMA, owing to its higher modulus the steel wire stiffens the arch and therefore the arch takes much higher load (over 30\% higher) while undergoing much less elastic deformation (nearly 50\% less than configuration 1). Therefore, a steel wire (replacing SMA) cannot ensure the desired large elastic deformation (and in the process, energy dissipation) of the landing gear subunit. We have also seen from analytical studies discussed earlier that although a helical steel spring (replacing SMA element) can give a deflection identical to that of configuration 1 the weight of the resulting landing gear is far too high (see Table 1). Figure 16 shows the comparison of analysis and testing for configuration 1. In configuration 2, when the SMA was not attached the arch took about $50 \%$ of the total load of $1000 \mathrm{~N}$. The vertical deflection at $1000 \mathrm{~N}$ load is $42 \mathrm{~mm}$. This can be seen from Fig. 17. The summary of the comparison relating to Figs. 16 and 17 is given in Table 4 . For configuration 2 , the test had to be stopped at $1000 \mathrm{~N}$ load, as there were indications of CFRP failure in compression on the inner surface of the arch. This was confirmed by the acoustic emissions, which were audible. The results indicate that the arch is getting stiffer when the SMA element is attached to it. The arch is able to share a higher load and thereby the total load carrying 


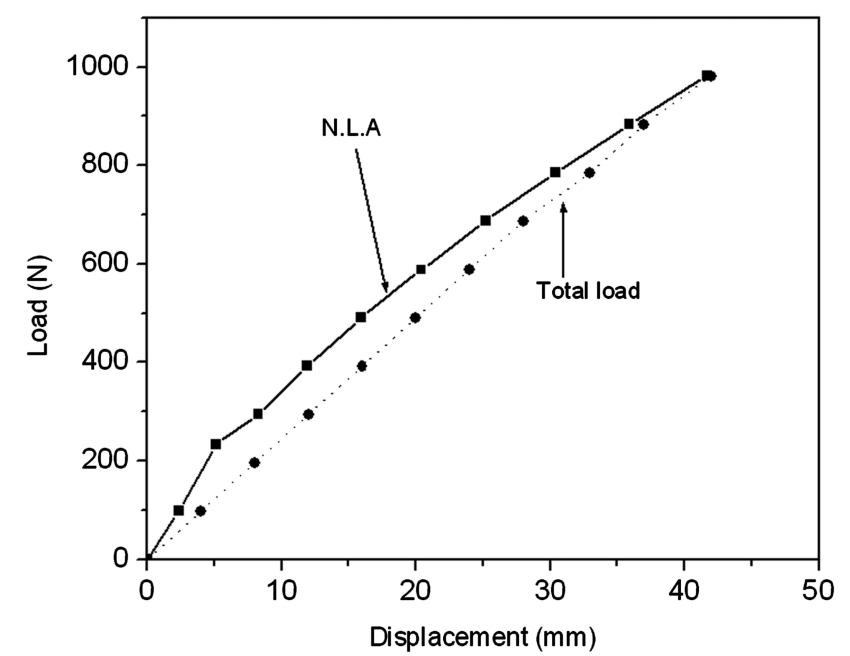

Fig. 17 Comparison of nonlinear analysis and experimental result; load vs vertical deflection $\left(\delta_{v}\right)$ for $\mathrm{C} 2$.

capacity of the landing gear increases. The total elastic deflection $\delta_{v}$ of the landing gear is increased from $42 \mathrm{~mm}$ without SMA to $49 \mathrm{~mm}$ with SMA at a maximum total vertical load of $1250 \mathrm{~N}$. In the smart landing gear the landing beam segment weighs about $5.8 \mathrm{~N}$ and the arch weighs about $4.4 \mathrm{~N}$ but the SMA weighs only about $0.05 \mathrm{~N}$. A small amount of SMA suitably placed $(0.5 \%$ of the total weight of the subunit) as in configuration 1 results in an increase of total load carrying capacity of the subunit by about $25 \%$ and increases the vertical elastic deformations by about $20 \%$. This clearly establishes the energy-dissipating superelastic character of the SMA element while it (SMA) undergoes an elastic deformation of more than $4 \%$ and dissipates energy. These characteristics ensure the desired soft landing for such types of vehicles. As can be seen from Table 4, there is a very good correlation between experiment and analysis for both the configurations, that is, with and without SMA. With the SMA element the maximum load carrying capacity increased from 1000 to $1250 \mathrm{~N}$. It can be seen that for configuration 1, the arch along with SMA takes slightly more than $50 \%$ of the total load, that is, $680 \mathrm{~N}$ of the total $1250 \mathrm{~N}$.

It has to be pointed out that both testing and analysis indicate roughly $50 \%$ of the total load going to the arch and SMA combination and $50 \%$ to the beam.

It is important to point out that sensory information from the SMA does not in any way improve the performance of the landing gear. The sensory information is used only to validate the design.

The simultaneous use of superelastic SMA as a sensor as it deforms and dissipates energy is proposed to be done in the following manner. A small current (100 mA) is passed through the superelastic SMA. This current is far less than the actuating current of about $2000 \mathrm{~mA}$ that would be required to energize a thermal NiTi base SMA of an identical diameter $(0.6 \mathrm{~mm})$. The change in length of the SMA is manifest as a change in voltage across SMA, measured in millivolts, when a small constant current of the order of about $100 \mathrm{~mA}$ is passed through the superelastic wire. The voltage signal is acquired using the necessary hardware interface, which is part of the blimp electronic circuitry. The voltage is converted to a frequency signal using a voltage-to-frequency converter mounted on the blimp. At the ground station the frequency signal is received and

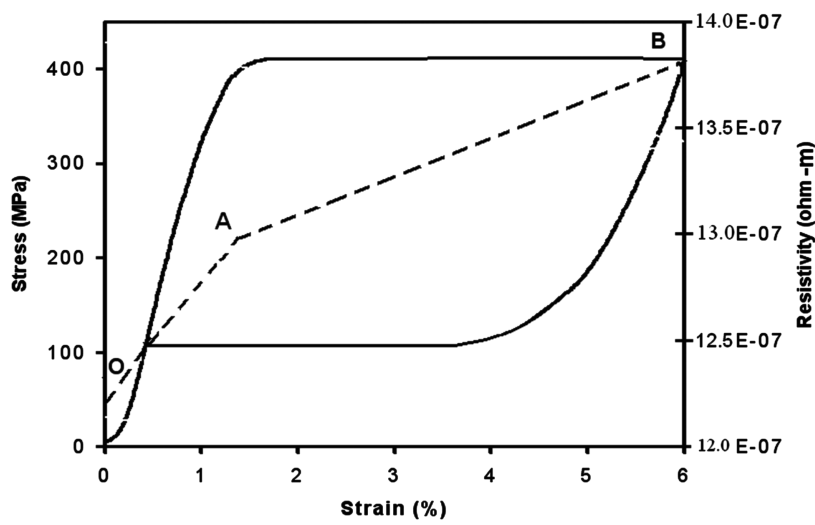

Fig. 18 Stress vs strain and resistivity vs strain for superelastic wire.

reconverted to a voltage signal. Electrical resistivity (calculated based on the acquired voltage change, area, and length across SMA) vs strain is a linear relationship during loading as shown in Fig. 18 (idealized). In this figure the resistivity vs strain curve OAB has two slopes. The first segment OA represents the elastic increase in length of austenite phase only. The second segment $\mathrm{AB}$ (superelastic) represents the change of phase in the plateau region of the stressstrain curve. Therefore, the changes in resistivity are far more pronounced in the segment $\mathrm{AB}$. It is clear that the change of phase (measured as a change in resistivity) is accompanied by a simultaneous change in length. The resistivity vs strain data shown in Fig. 18 (idealized) is only for the loading curve. For example, at point $\bar{O}$, the SMA length is $1000 \mathrm{~mm}$. At points $A$ and $B$ the SMA has undergone a change in length of 15 and $60 \mathrm{~mm}$, respectively. Every point on the curve $\mathrm{OAB}$ has a unique value of resistivity and SMA length. Thus, for a given value of voltage read at the ground station there is a corresponding value of resistivity and SMA length. For a given SMA length the corresponding value of the vertical deflections can be known. The change in length of the SMA is a clear indicator of the deformation characteristics of the arch and therefore that of the landing gear also. Therefore, this information is a useful sensory feedback (only to validate and if necessary) to modify the design of the smart landing gear.

\section{Conclusions}

An innovative combination of carbon composites (having high strength and high stiffness), natural cane (having relatively large elastic strain compared with CFRP), and superelastic SMA (with relatively large nonlinear elastic deformations and high energy dissipating characteristics) has been developed to realize the smart landing gear which can undergo large elastic deformations. The performance of the superelastic SMA based smart landing gear has been evaluated against an identical metal landing gear with helical springs and the superiority of the SMA based smart landing gear is well established. The combined assembly of arch (consisting of CFRP and cane) landing beam and SMA element in the smart landing gear has been studied using nonlinear FEM analysis and tested; there is good correlation between analysis and testing. The superior energy dissipating and recoil characteristics of superelastic SMA have been well exploited. The sensory characteristic while it is dissipating energy is also simultaneously used to validate the design. It is clear that a small amount of the SMA suitably placed results in a

Table 4 Summary of load sharing (derived from testing and analysis results) between arch, beam, and SMA

\begin{tabular}{lcccccccc}
\hline \hline LC & \multicolumn{2}{c}{ Total load, N } & \multicolumn{3}{c}{ Load sharing, N } & \multicolumn{2}{c}{ Deflection, mm } \\
\cline { 2 - 9 } & \multirow{2}{*}{ Testing } & Analysis & \multicolumn{2}{c}{ Testing } & \multicolumn{2}{c}{ Analysis } & Testing & Analysis \\
\cline { 3 - 8 } & & & Arch & Beam & Arch & Beam & $\delta_{v}$ & $\delta_{v}$ \\
\hline C1 & 1250 & 1250 & 680 & 570 & 690 & 560 & 49 & 42.1 \\
C1 & 1000 & 1000 & 580 & 420 & 618 & 382 & 37.0 & 27.2 \\
C2 & 1000 & 1000 & 503 & 497 & 479 & 521 & 42 & 41.9 \\
\hline \hline
\end{tabular}

${ }^{\mathrm{a}} \mathrm{C} 1$ : configuration 1 (beam, arch, and SMA); C2: configuration 2 (beam and arch). 
substantial increase of total load carrying capacity and vertical elastic deformations of the landing gear. An efficient landing gear with low weight and high energy dissipating characteristics for airships and other such vehicles has been successfully developed for a certain class of aerospace vehicles.

\section{Acknowledgments}

The authors wish to acknowledge A. R. Upadhya, National Aerospace Laboratories, Bangalore, for his constant encouragement. Sincere thanks to P. Senthil Kumar, H. V. Ramachandra, B. Ramanaiah, Satisha, A. S. Reddy, and R. Manikandan of Advanced Composites Division for their help.

\section{References}

[1] Norman, S. C., Aircraft Landing Gear Design: Principle and Practices, AIAA Education Series, AIAA, Washington, D.C., 1988.

[2] Del Monte, B., and Barone, R. P., United Technologies Corp., U.S. Patent for "A Crashworthy Landing Gear for an Aircraft," No. CA 2205489, Nov. 1994.

[3] Airoldi, A., and Janszen, G., "A Design Solution for a Crashworthy Landing Gear with a New Triggering Mechanism for the Plastic Collapse of Metallic Tubes," Journal of Aerospace Science and Technology, Vol. 9, 2005, pp. 445-455.

[4] Philips, N. S., Carr, R. W., and Scranton, R. S., "Crashworthy Landing Gear Study," U.S. Army Air Mobility Research and Development Laboratory Tech. Rept. 72-61, April 1973.

[5] Tho, C.-H., Sparks, C. E., Sareen, A. K., Smith, M. R., and Johnson, C., "Efficient Helicopter Skid Landing Gear Dynamic Drop Simulation Using LS-DYNA," Proceedings of the American Helicopter Society 59th Anпиаl Forum, American Helicopter Society International, Inc., Alexandria, VA, 2003

[6] Stephens, B. E., and Evans, W. L., "Application of Skid Landing Gear
Dynamic Drop Analysis," Proceedings of the American Helicopter Society 55th Annual Forum, American Helicopter Society International, Inc., Alexandria, VA, 1999.

[7] Airoldi, A., and Lanzi, L., "Multi-Objective Genetic Optimization for Helicopter Skid Landing Gears," Proceedings of the 46th AIAA/ASME/ ASCE/AHS/ASC Structures, Structural Dynamics, and Materials Conference, American Institute of Aeronautics and Astronautics, Inc., Washington, D.C., 2005.

[8] Sareen, A. K., Smith, M. R., and Howard, J. V., "Helicopter Skid Gear Dynamic Drop Analysis and Test Correlation," Proceedings of the American Helicopter Society 54th Annual Forum, American Helicopter Society International, Inc., Alexandria, VA, 1998.

[9] Van Humbeeck, J., "Shape Memory Alloys: A Material and a Technology," Journal of Advanced Engineering Materials, Vol. 3, No. 11, 2001, pp. 837-849.

[10] "Symposium on Newer Structural Materials for Aerospace Vehicles," American Society for Testing and Materials Special Tech. Pub. No. 379.

[11] DesRoches, R., McCormick, J., and Delemont, M., "Cyclic Properties of Superelastic Shape Memory Alloy Wires and Bars," Journal of Structural Engineering, Vol. 130, No. 1, Jan. 2004, pp. 38-46.

[12] Dolce, M., and Cardone, D., "Mechanical Behavior of Shape Memory Alloys for Seismic Applications," International Journal of Mechanical Sciences, Vol. 43, 2001, pp. 2657-2677.

[13] Nemat-Nasser, S., and Guo, W.-G., "Superelastic and Cyclic Response of NiTi SMA at Various Strain Rates and Temperatures," Mechanics of Materials, Vol. 38, 2006, pp. 463-474.

[14] Dayananda, G. N., Varughese, B., Harish Kumar, T. and Subba Rao, M., "Development of a SMA Based Smart Landing Gear for Rotorcraft and Other Similar Applications," Proceedings of 4th International Conference on Smart Materials, Structures and Systems, Institute of Smart Structures and Systems, Bangalore, India, 2005, p. SB06.

[15] Khoury, G. A., and Gillett, J. D., "Airship Technology," Cambridge Univ. Press, Cambridge, England, U.K., 1999. 